\title{
A Continuum Model of Solidification and Inclusion Collision- growth in the Slab Continuous Casting Caster
}

\author{
Hong LEI, Dian-Qiao GENG and Ji-Cheng HE \\ Key Laboratory of Electromagnetic Processing of Materials, Ministry of Education, Northeastern University, Shenyang, \\ 110004, China. E-mail: cn_leihong@yahoo.com
}

(Received on April 13, 2009; accepted on June 11, 2009)

\begin{abstract}
A coupled mathematical model on fluid flow, heat and solute transport, and inclusion transport is developed to investigate turbulent flow, solidification, and inclusion collision-growth in the slab continuous caster. The behaviors of inclusion and solute in the steel belong to mass transfer phenomena, but inclusion transport is different from solute transfer in the liquid phase zone, mush zone and solid phase zone. In the continuous caster, turbulent collision and Stokes collision, which are the major factor causing inclusions to coalescence, have been taken into account in the mathematical model. All these differential equations have the same basic structure and can be solved by the same numerical method. Influenced by the fluid flow, the temperature, carbon element and inclusion in the molten steel have similar spatial distribution as the fluid flow in the continuous caster. Their spatial distribution can be divided into the upper and lower recirculation zones, but their distributions have their own characteristics. Near the center of the recirculation zones, the temperature of molten steel and the characteristic inclusion concentration and the characteristic inclusion number density are lower, but the carbon concentration and the inclusion size are greater. Due to the interaction between the movement of solidified shell and the downward flow, a small corner-vortex appears near the meniscus. The initial solidified shell forms near the meniscus, so there is a few of indigenous inclusions with small size in the initial solidified shell.
\end{abstract}

KEY WORDS: turbulent flow; solidification; solute transfer; inclusion; Stokes collision; turbulent collision.

\section{Introduction}

Over the last three decades, there have been numerous studies about the transport phenomena in the continuous casting processes for slab, billet, and bloom caster. Fluid flow plays an important role in determining heat, solute and inclusion transport in the continuous casting process. And there has been a steady stream of research papers about fluid flow in the continuous casting mold. ${ }^{1,2}$ The appearance of more powerful computers gives us a chance to deal with coupled multiphase phenomena. Researchers start to pay more attentions to the coupled mathematical model on turbulent flow, heat and solute transfer in the continuous casting process., ${ }^{3,4)}$ Inclusion behavior in the continuous caster is a particularly challenging task because it frequently requires the investigator to deal with the collisioncoalescence among inclusions. Trajectory model ${ }^{3,5)}$ and inclusion mass conservation model ${ }^{6,7)}$ are employed to investigate inclusion behavior in the continuous casting mold, but it can not consider the collision among inclusions. Inclusion mass-population conservation model ${ }^{8,9)}$ and inclusion fractal-growth model ${ }^{10)}$ can treat with the collisioncoalescence in the liquid zone of the mold successfully. But until now, all these mathematical models about inclusion behaviors in the continuous caster ignored Stokes collision, and did not consider the inclusion behavior in the mush zone and solid phase zone.

In this paper, we developed a coupled mathematical model capable of predicting the three-dimensional aspect of fluid flow, heat and solute transfer, and inclusion behavior occurring in the slab continuous caster. The current mathematical model has three new features. Firstly, turbulent collision and Stokes collision are taken into account to describe inclusion coalescence in the continuous casting mold. Secondly, inclusion transports have different characteristics in liquid phase zone, mush zone and solid phase zone. Thirdly, symmetry boundary condition is applied at the mold wall in the inclusion mass-population conservation model. And then the finite-volume method is applied to solve the governing equations on the base of the same structure of these differential equations. Finally, numerical simulation technique is used to investigate the transfer phenomena in the slab continuous caster.

\section{Mathematical Formulation}

\subsection{Assumption}

Due to the complexity of the transfer phenomena, the following assumptions have been incorporated in the present mathematical model.

(1) The carbon steel is assumed to be a binary $\mathrm{Fe}-\mathrm{C}$ alloy. 
Table 1. Vector, scalar, diffusion coefficients and source terms in conservation equations.

\begin{tabular}{|c|c|c|c|c|}
\hline Equations & $\vec{U}$ & $\varphi$ & $\Gamma$ & $S$ \\
\hline Mass & $\vec{u}_{s} f_{s}+\vec{u}_{1} f_{1}$ & 1 & 0 & 0 \\
\hline Momentum ${ }^{[4]}$ & $\overrightarrow{\mathrm{u}}_{\mathrm{s}} \mathrm{f}_{\mathrm{s}}+\overrightarrow{\mathrm{u}}_{\mathrm{l}} \mathrm{f}_{\mathrm{I}}$ & $u_{\mathrm{fi}}$ & $\rho v_{0}+\rho v_{t}$ & $\begin{array}{l}-\nabla \mathrm{p}+\rho \overrightarrow{\mathrm{g}}\left[\beta_{\mathrm{T}} \Delta \mathrm{T}+\beta_{\mathrm{C}} \Delta \mathrm{C}\right] \\
-\frac{\mu_{1}}{\mathrm{~K}_{\mathrm{p}}}\left(\overrightarrow{\mathrm{u}}-\overrightarrow{\mathrm{u}}_{\mathrm{s}}\right)\end{array}$ \\
\hline k & $\overrightarrow{\mathrm{u}}_{\mathrm{s}} \mathrm{f}_{\mathrm{s}}+\overrightarrow{\mathrm{u}}_{\mathrm{l}} \mathrm{f}_{\mathrm{l}}$ & $\mathrm{k}$ & $\frac{\rho v_{\text {eff }}}{\sigma_{k}}$ & $G-\rho \varepsilon$ \\
\hline$\varepsilon$ & $\overrightarrow{\mathrm{u}}_{\mathrm{s}} \mathrm{f}_{\mathrm{s}}+\overrightarrow{\mathrm{u}}_{\mathrm{l}} \mathrm{f}_{\mathrm{l}}$ & $\varepsilon$ & $\frac{\rho v_{\text {eff }}}{\sigma_{\varepsilon}}$ & $\mathrm{C}_{1} \mathrm{G} \frac{\varepsilon}{\mathrm{k}}-\mathrm{C}_{2} \rho \frac{\varepsilon^{2}}{\mathrm{k}}$ \\
\hline Energy $^{[4]}$ & $\left(\overrightarrow{\mathrm{u}}_{\mathrm{s}} \mathrm{f}_{\mathrm{s}}+\overrightarrow{\mathrm{u}}_{\mathrm{l}} \mathrm{f}_{\mathrm{l}}\right) \mathrm{C}_{\mathrm{p}}$ & $\mathrm{T}$ & $\mathrm{f}_{\mathrm{s}} \mathrm{K}_{\mathrm{s}}+\mathrm{f}_{1}\left(\mathrm{~K}_{1}+\frac{\rho v_{\mathrm{t}} \mathrm{C}_{\mathrm{p}}}{\mathrm{Pr}_{\mathrm{t}}}\right)$ & $\rho \Delta \mathrm{H}_{\mathrm{f}} \overrightarrow{\mathrm{u}} \cdot \nabla \mathrm{f}_{\mathrm{s}}$ \\
\hline Solute ${ }^{[3]}$ & $\vec{u}_{s} f_{s}+\vec{u}_{1} f_{1}$ & $\mathrm{C}_{\mathrm{C}}$ & $\mathrm{f}_{\mathrm{s}} \rho \mathrm{D}_{\mathrm{Cs}}+\mathrm{f}_{1}\left(\rho \mathrm{D}_{\mathrm{Cl}}+\frac{\rho v_{\mathrm{t}}}{\mathrm{Sc}_{\mathrm{t}}}\right)$ & $\begin{array}{l}\nabla \cdot\left[\rho \mathrm{f}_{\mathrm{s}} \mathrm{D}_{\mathrm{Cs}} \nabla\left(\mathrm{C}_{\mathrm{Cs}}-\mathrm{C}_{\mathrm{C}}\right)\right] \\
+\nabla \cdot\left[\rho \mathrm{f}_{\mathrm{l}}\left(\mathrm{D}_{\mathrm{Cl}}+\frac{\rho v_{\mathrm{t}}}{\mathrm{Sc}_{\mathrm{t}}}\right) \nabla\left(\mathrm{C}_{\mathrm{Cl}}-\mathrm{C}_{\mathrm{C}}\right)\right] \\
-\nabla \cdot\left[\rho\left(\mathrm{C}_{\mathrm{Cl}}-\mathrm{C}_{\mathrm{C}}\right)\left(\overrightarrow{\mathrm{u}}-\overrightarrow{\mathrm{u}}_{\mathrm{s}}\right)\right]\end{array}$ \\
\hline $\mathrm{C}^{*}$ & $\overrightarrow{\mathrm{u}}_{\mathrm{c}^{*}}$ & $\mathrm{C}^{*}$ & $f_{1}\left(\rho D_{\text {in }}+\frac{\rho v_{t}}{S c_{t}}\right)$ & 0 \\
\hline $\mathrm{N}^{*}$ & $\overrightarrow{\mathrm{u}}_{\mathrm{N}^{*}}$ & $\mathrm{~N}^{*}$ & $f_{1}\left(\rho D_{\text {in }}+\frac{\rho v_{t}}{S c_{t}}\right)$ & $\begin{array}{l}-2.6 \alpha\left(\frac{\pi \varepsilon}{v}\right)^{\frac{1}{2}} \mathrm{~N}^{* 2} \mathrm{r}^{* 3} \\
-\frac{10}{9 \sqrt[3]{6}} \frac{\pi \mathrm{g} \Delta \rho}{\mu} \mathrm{N}^{* 2} \mathrm{r}^{* 4}\end{array}$ \\
\hline
\end{tabular}

(2) The molten steel behaves as an incompressible Newtonian fluid, and turbulence effects are approximated by using the popular $k-\varepsilon$ turbulence model.

(3) The solid phase is rigid and moves downwards at the casting speed.

(4) Local thermodynamic equilibrium during solidification is assumed to prevail in this study.

(5) Except for the latent heat release, heat effects associated with solid phase transformation reactions are not taken into account.

(6) Only the vertical part of the caster is considered, and the strand curvature due to bending and the effect of strand deformation (bulging) are not taken into account.

(7) Darcy's law is applied as the flow resistance through mushy zone.

(8) The inclusions are spherical.

(9) Every inclusion moves independently until two inclusions collide and coalesce.

(10) The presence of the inclusions does not influence fluid flow and heat transfer due to their relatively low volume fraction within the steel.

(11) Some of inclusions reaching the free surface are again entrained into the molten steel. The analysis assumes that $80 \%$ of the inclusion flux which reaches the free surface is removed with the remaining $20 \%$ again entrained into the molten steel. ${ }^{8)}$

(12) The inclusions in steel come from indigenous inclusions, and exogenous inclusions are not taken into account.

\subsection{Fluid Flow, Heat and Solute Transport}

Due to the forced-convective flow in the mold region, the fluid flow in this process is essentially in the turbulent regime. In the present study, the popular $k-\varepsilon$ turbulence model is employed to account for the turbulent effects in the liquid region and the mushy zone. The governing equations of fluid flow, solidification and solute transport, are summarized in Table 1. Details on derivation of the above equations can be found in references. ${ }^{3,4)}$ Lever rule is employed to describe solute redistribution during the solidification process of $\mathrm{Fe}-\mathrm{C}$ alloy, and the solid fraction $f_{s}$ is assumed to be linearly proportional to the temperature ${ }^{4,11)}$ as

$$
f_{s}= \begin{cases}1 & T>T_{l} \\ \frac{T_{l}-T}{T_{l}-T_{s}} & T_{s} \leq T \leq T_{l} \\ 0 & T \leq T_{s}\end{cases}
$$

where $T_{l}$ and $T_{s}$ are liquidus temperature and solidus temperature, respectively.

\subsection{Inclusion Transport}

Industrial experiments ${ }^{12-16)}$ indicate that the fractional inclusion number density decrease exponentially as the inclusion radius increase, $n_{i}=A e^{-B r_{i}}$, where $A$ and $B$ are constants, which are related to the time and the position in the continuous caster. Then the characteristic inclusion number density, the characteristic inclusion volume concentration and the characteristic inclusion radius can be expressed as follows ${ }^{8,17)}$ :

$$
N^{*}=\int_{0}^{\infty} f(r) d r=\frac{A}{B}
$$




$$
\begin{gathered}
C^{*}=\int_{0}^{\infty} \frac{4}{3} \pi r^{3} f(r) d r=8 \pi \frac{A}{B^{4}} \\
r^{*}=\sqrt[3]{\frac{\int_{0}^{\infty} \frac{4}{3} \pi r^{3} f(r) d r}{\frac{4}{3} \pi N^{*}}}=\frac{\sqrt[3]{6}}{B}
\end{gathered}
$$

Thus, inclusion mass-population conservation model ${ }^{8)}$ can be represented by the following equations

$$
\begin{gathered}
\frac{\partial}{\partial x_{i}}\left(\rho \vec{u}_{C^{*}, i} C^{*}\right)=\frac{\partial}{\partial x_{i}}\left(D_{\text {eff }} \frac{\partial C^{*}}{\partial x_{i}}\right)+S_{C^{*}} \ldots \ldots \ldots . .(5) \\
\frac{\partial}{\partial x_{i}}\left(\rho \vec{u}_{N^{*}, i} N^{*}\right)=\frac{\partial}{\partial x_{i}}\left(D_{\text {eff }} \frac{\partial N^{*}}{\partial x_{i}}\right)+S_{N^{*}} \ldots \ldots \ldots(6) . .(6)
\end{gathered}
$$

In the current model, $S_{C^{*}}$ is zero because there is no chemical reaction related to the formation and disappearance of inclusions, $S_{N^{*}}$ is negative depending on the production of new inclusions due to the collision and coalescence, shown in Table 1 and Appendix.

\section{General Governing Equations}

Table 1 shows the basic structure of all these differential equations involves the convective and diffusive transport of physical variables. Thus, all these differential equations can be expressed as a general differential equation

$$
\nabla \cdot(\rho \vec{U} \varphi)=\nabla \cdot(\Gamma \nabla \varphi)+S
$$

The three terms in the general differential equation are the convection term, the diffusion term and the source term $S .{ }^{18)}$ The velocity $\vec{U}$ and the dependent variable $\varphi$ can stand for a variety of different physical quantities. And $\Gamma$ in the diffusion terms represents a diffusion coefficient for physical quantity $\varphi$. For example, if $\vec{U}$ is replaced by $\vec{u}_{p, C^{*}}$ and the dependent variable $\varphi$ is replaced by $C^{*}$, the general differential equations represents the characteristic inclusion mass conservation equation.

The inclusion transport equation is similar to the solute transport equation, but there are many differences between their own transport processes. Firstly, the liquid ahead of the solid-liquid interface is enriched by the solute elements owing to the rejection of solute into the liquid during the growth of the solidified shell. Such a phenomenon is called as solute segregation. But there is no redistribution for inclusion at the solid-liquid interface. Secondly, inclusions cannot move in the solid steel but there is solute transfer due to diffusion in the solid steel. Thirdly, there are different producing mechanisms for source term in the inclusion transport equations and the solute transport equation. The collision-growth among inclusions affects the inclusion population source term, and the chemical reaction affects the inclusion mass and population source terms. But the redistribution of solute at solid-liquid interface affects the solute mass source term. Fourthly, the velocity $\vec{U}$ in solute transport equation is equal to the velocity of the mixture (solid-liquid) phase $\vec{u}$, but the characteristic inclusion con- centration velocity $\vec{u}_{C^{*}}$ and the characteristic inclusion number-density velocity $\vec{u}_{N^{*}}$ in inclusion transport model is determined by the velocity of the mixture phase and the characteristic inclusion flotation velocity $\vec{u}_{p, C^{*}, z}$ and the characteristic inclusion number-density flotation velocity $\vec{u}_{p, N^{*}, z}$, respectively.

$$
\begin{aligned}
& \vec{u}_{C^{*}}=\left(\vec{u}_{l}+\vec{u}_{p, C^{*}, z}\right) f_{l}+\vec{u}_{s} f_{s} \\
& \vec{u}_{N^{*}}=\left(\vec{u}_{l}+\vec{u}_{p, N^{*}, z}\right) f_{l}+\vec{u}_{s} f_{s}
\end{aligned}
$$

with

$$
\begin{aligned}
u_{p, C^{*}, z}= \begin{cases}\frac{2}{\sqrt[3]{6^{2}}} \frac{2}{9} \cdot \frac{\Delta \rho g}{\mu} r^{* 2} & \mathrm{Re}_{p} \leq 2 \\
\frac{1}{\sqrt[3]{6}}\left(\frac{4 \sqrt{2}}{15} \cdot \frac{g \Delta \rho}{\sqrt{\rho \mu}}\right)^{2 / 3} r^{*} & 2<\mathrm{Re}_{p} \leq 500 \\
\frac{\sqrt{\pi}}{2 \sqrt[6]{6}}\left(\frac{8}{3} \cdot \frac{\Delta \rho g}{0.44 \rho}\right)^{1 / 2} r^{* 1 / 2} & \mathrm{Re}_{p}>500\end{cases} \\
u_{p, N^{*}, z}= \begin{cases}\frac{20}{\sqrt[3]{6^{2}}} \frac{2}{9} \cdot \frac{\Delta \rho g}{\mu} r^{* 2} & \operatorname{Re}_{p} \leq 2 \\
\frac{4}{\sqrt[3]{6^{2}}}\left(\frac{4 \sqrt{2}}{15} \cdot \frac{g \Delta \rho}{\sqrt{\rho \mu}}\right)^{2 / 3} r^{*} & 2<\mathrm{Re}_{p} \leq 500 \\
\frac{35 \sqrt{\pi}}{32 \sqrt[6]{6}}\left(\frac{8}{3} \cdot \frac{\Delta \rho g}{0.44 \rho}\right)^{1 / 2} r^{* 1 / 2} & \operatorname{Re}_{p}>500\end{cases}
\end{aligned}
$$

where $f_{l}$ is the liquid fraction. $\vec{u}_{l}$ and $\vec{u}_{s}$ are the velocities of liquid phase and solid phase, respectively. $\rho$ is the density of molten steel, $\Delta \rho$ is the difference between the inclusion density and the density of molten steel, $g$ is the gravitational acceleration, $\mu$ is the molecular dynamic viscosity of molten steel, and $\mathrm{Re}_{p}$ is the particle Reynolds number.

The effective diffusion coefficient for inclusion is

$$
D_{\text {eff }}=\left(D_{0}+\frac{v_{t}}{\mathrm{Sc}_{t}}\right) f_{l}
$$

where $v_{t}$ is the turbulent kinematic viscosity of molten steel, $\mathrm{Sc}_{t}$ is turbulent Schmidt number, and $D_{0}$ is the diffusion coefficient.

\section{Boundary Condition and Numerical Solution Method}

Due to the geometric symmetry, only half of the continuous caster is considered for the analysis. The boundary conditions for fluid flow, heat and solute transfer can be found in the Refs. 3), 4), 11). Detailed descriptions of boundary conditions for inclusion transport are shown in Table 2. Specifications of the modeled continuous caster and the thermophysical properties of the carbon steel are listed in Table 3. In the previous papers, ${ }^{8,9,19,20)}$ it is assumed that the mold wall can trap the inclusion near the mold wall because 
Table 2. Boundary conditions for inclusion transport.

\begin{tabular}{llr}
\hline & $C^{*}$ & $N^{*}$ \\
\hline Free surface & $\mathrm{F}_{\mathrm{C}^{*}}=0.8\left(\mathrm{u}_{\mathrm{C}^{*}, \mathrm{Z}} \mathrm{C}^{*}+\mathrm{D}_{\text {eff }} \frac{\partial \mathrm{C}^{*}}{\partial \mathrm{n}}\right)$ & $\mathrm{F}_{\mathrm{N}^{*}}=0.8\left(\mathrm{u}_{\mathrm{N}^{*}, \mathrm{Z}} \mathrm{N}^{*}+\mathrm{D}_{\mathrm{eff}} \frac{\partial \mathrm{N}^{*}}{\partial \mathrm{n}}\right)$ \\
Inlet & $\mathrm{C}^{*}=\mathrm{C}_{0}^{*}$ & $\mathrm{~N}^{*}=\mathrm{N}_{0}^{*}$ \\
Wall & $\frac{\partial \mathrm{C}^{*}}{\partial \mathrm{n}}=0$ & $\frac{\partial \mathrm{N}^{*}}{\partial \mathrm{n}}=0$ \\
plane & $\frac{\partial \mathrm{C}^{*}}{\partial \mathrm{n}}=0$ & $\frac{\partial \mathrm{N}^{*}}{\partial \mathrm{n}}=0$ \\
Outlet & $\frac{\partial \mathrm{C}^{*}}{\partial \mathrm{n}}=0$ & $\frac{\partial \mathrm{N}^{*}}{\partial \mathrm{n}}=0$ \\
\hline
\end{tabular}

Table 3. Main dimensions and parameters.

\begin{tabular}{|c|c|c|}
\hline Variable & unit & value \\
\hline Thermal conductivity of solid steel & $\mathrm{W} \cdot \mathrm{m}^{-1} \cdot \mathrm{K}^{-1}$ & $34.0^{[21]}$ \\
\hline Thermal conductivity of liquid steel & $\mathrm{W} \cdot \mathrm{m}^{-1} \cdot \mathrm{K}^{-1}$ & $27.0^{[21]}$ \\
\hline Specific heat(liquid or solid) & $\mathrm{J} \cdot \mathrm{kg}^{-1} \cdot \mathrm{K}^{-1}$ & $720.0^{[21]}$ \\
\hline Latent heat of fusion & $\mathrm{kJ} \cdot \mathrm{kg}^{-1}$ & $270.0^{[22]}$ \\
\hline Liquidus temperature & ${ }^{\circ} \mathrm{C}$ & 1532.7 \\
\hline Solidus temperature & ${ }^{\circ} \mathrm{C}$ & 1506.9 \\
\hline Melt superheat & ${ }^{\circ} \mathrm{C}$ & 20.0 \\
\hline Casting speed & $\mathrm{m} \cdot \mathrm{s}^{-1}$ & 2.0 \\
\hline Viscosity of molten steel & $\mathrm{kg} \cdot \mathrm{m}^{-1} \cdot \mathrm{s}^{-1}$ & $0.0061^{[8]}$ \\
\hline Density of steel & $\mathrm{kg} \cdot \mathrm{m}^{-3}$ & $7100^{[8]}$ \\
\hline Density of inclusions & $\mathrm{kg} \cdot \mathrm{m}^{-3}$ & $3960^{[8]}$ \\
\hline Slab width & $\mathrm{m}$ & 1.4 \\
\hline Slab thickness & $\mathrm{m}$ & 0.23 \\
\hline Mold length & $\mathrm{m}$ & 0.9 \\
\hline Caster length simulated & $\mathrm{m}$ & 3.0 \\
\hline Nozzle port & $\mathrm{m}$ & $0.085 \times 0.065$ \\
\hline Nozzle submergence length & $\mathrm{m}$ & 0.034 \\
\hline Nozzle angle & $\circ$ & 15, downward \\
\hline Carbon mass content & - & $0.065 \%$ \\
\hline Thermal expansion coefficient & ${ }^{\circ} \mathrm{C}^{-1}$ & $1.0 \times 10^{-4}[3]$ \\
\hline Solutal expansion coefficient & - & $4.0 \times 10^{-3}[3]$ \\
\hline Diffusion coefficient of $\mathrm{C}$ in liquid steel & $\mathrm{m}^{2} \cdot \mathrm{s}^{-1}$ & $1.0 \times 10^{-8}[3]$ \\
\hline Diffusion coefficient of $\mathrm{C}$ in solid steel & $\mathrm{m}^{2} \cdot \mathrm{s}^{-1}$ & $1.6 \times 10^{-11[3]}$ \\
\hline $\begin{array}{l}\text { Diffusion coefficient of inclusions in } \\
\text { liquid steel }\end{array}$ & $\mathrm{m}^{2} \cdot \mathrm{s}^{-1}$ & Stokes-Einstein equation ${ }^{[24]}$ \\
\hline $\begin{array}{l}\text { Diffusion coefficient of inclusions in solid } \\
\text { steel }\end{array}$ & $\mathrm{m}^{2} \cdot \mathrm{s}^{-1}$ & 0 \\
\hline Equilibrium partition ratio & & $0.2^{[3]}$ \\
\hline Heat loss in the mold & $\mathrm{W} \cdot \mathrm{m}^{-2}$ & empirical formula $^{[4]}$ \\
\hline Spray heat transfer coefficient & $\mathrm{W} \cdot \mathrm{m}^{-2} \cdot \mathrm{C}^{-1}$ & $750^{[23]}$ \\
\hline Heat loss at the top surface & $\mathrm{W} \cdot \mathrm{m}^{-2}$ & $15,000^{[20]}$ \\
\hline
\end{tabular}

there is a thin solidified shell to trap the inclusions. But in fact, the inclusions cannot move in the solidified shell, so symmetric boundary condition is applied at the mold wall in the current mathematical model.

The calculation domain was discretized by using a nonuniform grid of 50 (longitudinal) $\times 75$ (vertical) $\times 90$ (transverse) elements with a densely packed grid near the solidified shell. All the differential equations have the same basic structure, so they can be solved by the finite-volume

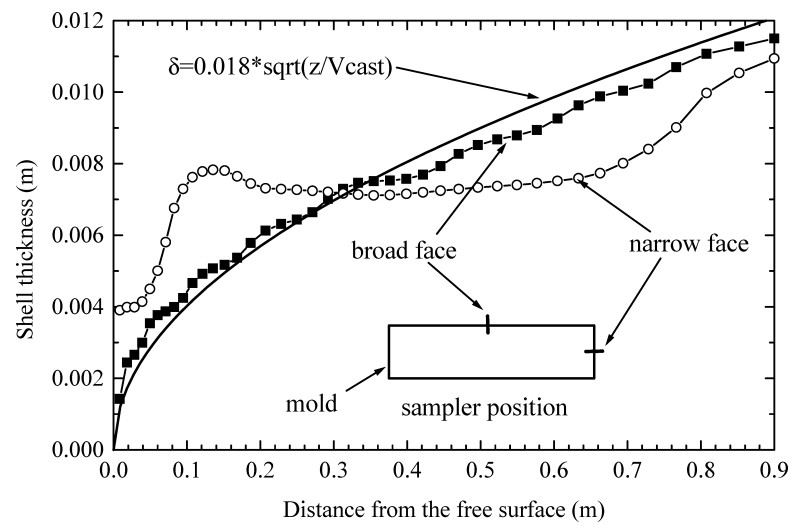

Fig. 1. Shell thickness at the direction of casting speed.

method on the base of staggered grid, ${ }^{18)}$ and coding days decrease. Specifically, the scalars (pressure, kinetic energy, kinetic energy dissipation rate, characteristic inclusion concentration, characteristic inclusion number density and characteristic inclusion radius) were evaluated at the grid nodes while the vectors (velocity components) were defined at the interface between the grid nodes.

The discretized equations were solved using the tri-diagonal matrix algorithm coupled with the Gauss-Siedel routine. In order to avoid divergence in the iterative solution, under-relaxation was employed. The converged solution should satisfy the follows rules:

(1) The mass source term in the pressure-correction equation was less than $10^{-6}$.

(2) The ratio of the difference between the steel input and output mass fluxes to the steel input mass flux is less than $0.1 \%$.

(3) The ratio of the difference between the solute input and output mass fluxes to the solute input mass flux is less than $1.0 \%$.

(4) The ratio of the difference between the inclusion input and output mass fluxes to the inclusion input mass flux is less than $0.2 \%$.

\section{Results and Discussion}

\subsection{Modeling Verification}

In order to validate the codes, we compare the numerical results with the experimental results. For the fluid flow, the numerical results are in a good agreement with water-base and liquid Sn-based experimental data. ${ }^{25)}$ For the solidification, the predicted shell thickness is the distance from the mold wall to the surface at which the solid fraction is 0.7 , as shown in Fig. 1. The predicted shell thickness on the broad shell agrees well with the experimental data, ${ }^{11)}$ but there is great difference between the predicted shell thickness on the narrow shell and the experimental data. ${ }^{11)}$ And the ' $W$ ' shape distribution of inclusion characteristic number density have been verified by Javurek's experiment. ${ }^{8)}$

\subsection{Turbulent Flow, Heat and Solute Transport}

Figure 2(a) shows the fluid flow in the mold. The jet from submerged entry nozzle impinges on the narrow face of the mold and is divided into upward flow and downward flow. Confined by the free surface and the solidified shells, 


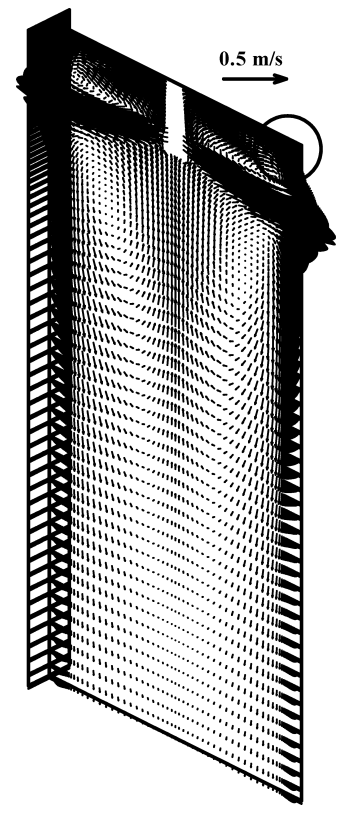

Fig. 2. Velocity field.

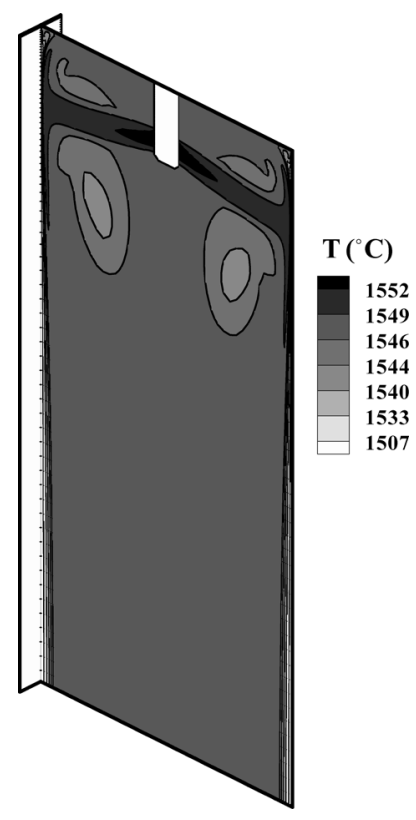

Fig. 3. Temperature field.

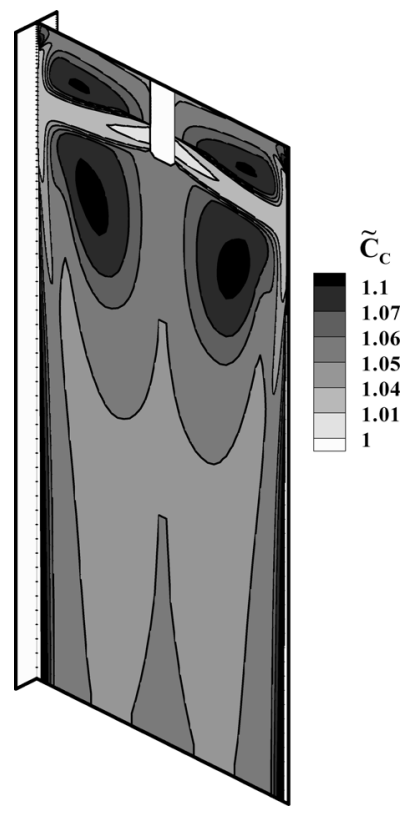

Fig. 4. Solute segregation. the upward flow forms the upper recirculation zone. Confined by the solidified shells and the return flow towards submerged entry nozzle, the downward flow forms the lower recirculation.

Figure 3 shows the jet from submerged entry nozzle has the higher temperature than other parts inside the continuous caster, and the temperature of molten steel decreases gradually during the marching of molten steel. And the temperature gradient is greater near the narrow face because there are stronger heat convection and the continuous release of the latent heat of fusion during the growth of solidified shell.

Figure 1 shows that the predicted shell thickness on the narrow shell is different from that on the broad face. Three reasons lead to this phenomenon. Firstly, part of solidified shell near the impinging point melts away after the fresh molten steel with higher temperature impinges the solidified shell on the narrow face. Consequently, there is a minimum shell thickness at the impinging point. Secondly, there is strong heat transfer near the corner of the mold, so the shell thickness on the narrow face is greater than that on the broad face near the meniscus. Thirdly, the downward steam with higher temperature along with the solidified shell also causes parts of solidified shell on the narrow face to melt, so the shell thickness on the narrow face is less than that on the broad face under the impinging point.

As solidification proceeds, the mushy zone ahead of the solid-liquid interface is enriched by carbon elements due to the rejection of solute into the liquid phase. The rejected solute is redistributed and mixed by the diffusion and convection transfer, and leads to centerline segregation. The level of segregation is defined by the segregation ratio or degree of segregation $\tilde{C}_{C}=C_{C} / C_{C 0}$, where $C_{C}$ is equal to the local carbon concentration and $C_{C 0}$ is the carbon concentration at the inlet. Figure 4 shows the jet from submerged entry nozzle has the lower carbon concentration than other parts inside the mold, and the carbon concentration of molten steel increases gradually during the marching of molten steel.
Figures 3 and 4 also show that temperature distribution and carbon concentration distribution also have the upper and lower recirculation zones, which is similar to velocity field. But the carbon concentration is higher and the temperature is lower at the center of the recirculation zone. Two reasons lead to such interesting phenomena. Firstly, fluid flow is the key factor to affect the heat and solute transport, and turbulent diffusion and convective transfer are two main transport mechanisms. Secondly, during the growth of the solidified shell, the rejected solute ahead of solid-liquid interface is redistributed and mixed by convection and turbulent diffusion. But the velocity near the center of the recirculation zone is so small that the fresh molten steel with higher temperature and low carbon concentration cannot reach the center of the recirculation.

\subsection{Collision Mechanisms}

There are three collision modes: Brownian collision, Stokes collision and turbulent collision, so the dimensionless collision numbers, $\omega$, is introduced to measure the relative magnitudes of the different collision mechanisms.

$$
\begin{gathered}
\omega\left(\beta_{S}, \beta_{B}\right)=\frac{\beta_{S}}{\beta_{B}}=\frac{g \pi \Delta \rho}{3 k T}\left|r_{i}-r_{j}\right|\left(r_{i}+r_{j}\right) r_{i} r_{j} \ldots . . \\
\omega\left(\beta_{T}, \beta_{B}\right)=\frac{\beta_{T}}{\beta_{B}}=\frac{1.95 \mu(\pi \varepsilon / v)^{1 / 2}}{k T}\left(r_{i}+r_{j}\right) r_{i} r_{j} \ldots \\
\omega\left(\beta_{T}, \beta_{S}\right)=\frac{\beta_{T}}{\beta_{S}}=\frac{5.85 \mu(\pi \varepsilon / v)^{1 / 2}}{g \pi \Delta \rho} \frac{1}{\left|r_{i}-r_{j}\right|} \ldots . .
\end{gathered}
$$

Figure 5 shows the isometric contours of the dimensionless collision numbers. In the mold, the turbulent energy dissipation rate is above $0.001 \mathrm{~m}^{2} / \mathrm{s}^{3},{ }^{8)}$ so the turbulent collision is estimated on the condition of $\varepsilon=0.001 \mathrm{~m}^{2} / \mathrm{s}^{3}$ and $\varepsilon=0.01 \mathrm{~m}^{2} / \mathrm{s}^{3}$. If the inclusion size is less than $1 \mu \mathrm{m}$, Brownian collision is the major factor causing inclusion to collide with each other, turbulent collision has the minor effect and Stokes collision can be ignored. If the inclusion 


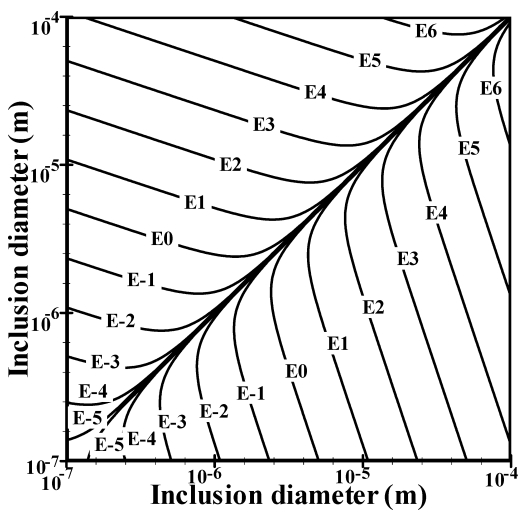

(a) $\omega\left(\beta_{\mathrm{S}}, \beta_{\mathrm{B}}\right)$

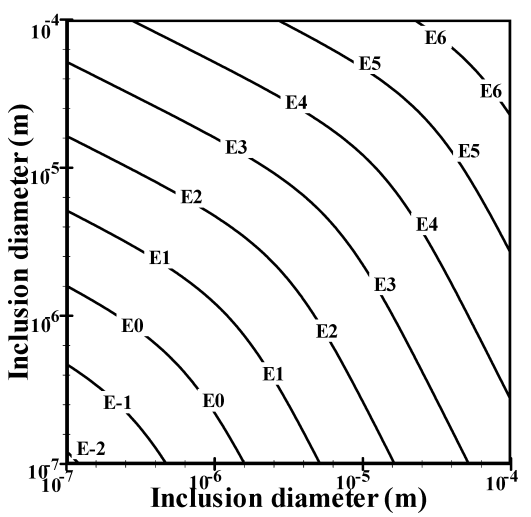

(b) $\omega\left(\beta_{\mathrm{T}}, \beta_{\mathrm{B}}\right) \quad\left(\varepsilon=10^{-3} \mathrm{~m}^{2} / \mathrm{s}^{3}\right)$

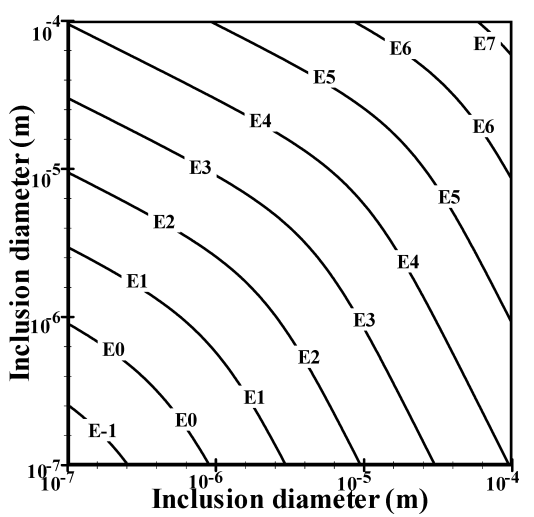

(c) $\omega\left(\beta_{\mathrm{T}}, \beta_{\mathrm{B}}\right)\left(\varepsilon=10^{-2} \mathrm{~m}^{2} / \mathrm{s}^{3}\right)$

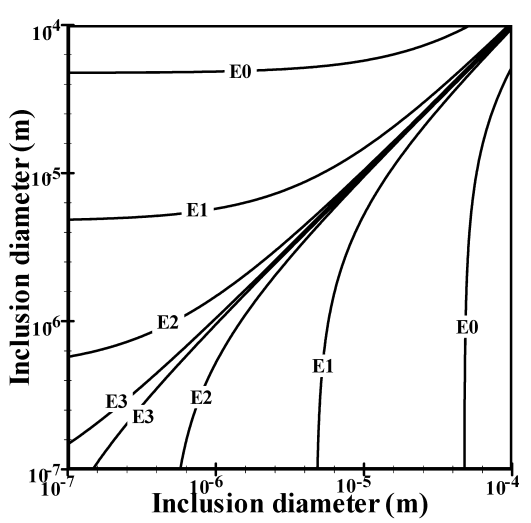

(d) $\omega\left(\beta_{\mathrm{T}}, \beta_{\mathrm{s}}\right)\left(\varepsilon=10^{-3} \mathrm{~m}^{2} / \mathrm{s}^{3}\right)$

Fig. 5. Comparison between different collision mechanism. (a) $\omega\left(\beta_{S}, \beta_{B}\right)$, (b) $\omega\left(\beta_{T}, \beta_{B}\right)\left(\varepsilon=10^{-3} \mathrm{~m}^{2} / \mathrm{s}^{3}\right)$, (c) $\omega\left(\beta_{T}, \beta_{B}\right)$ $\left(\varepsilon=10^{-3} \mathrm{~m}^{2} / \mathrm{s}^{3}\right),(\mathrm{d}) \omega\left(\beta_{T}, \beta_{B}\right)\left(\varepsilon=10^{-3} \mathrm{~m}^{2} / \mathrm{s}^{3}\right)$. size is in the range from 1 to $10 \mu \mathrm{m}$, turbulent collision is the major factor. Brownian collision and Stokes collision have the minor effect, and the related collision rates are in the same order. If the inclusion size is greater than $10 \mu \mathrm{m}$, turbulent collision and Stokes collision are the major factors, and the related collision rates are 100-1 000000 times greater than Brownian collision rate. The inclusions less than $5 \mu \mathrm{m}$ are harmless to the slab quality and there is few indigenous inclusions larger than $100 \mu \mathrm{m}$. Thus, turbulent collision and Stokes collision are taken into account in the current mathematical model.

\subsection{Inclusion Behaviors}

Figures 6-8 show the jet from submerged entry nozzle has the greater characteristic inclusion concentration, the greater characteristic inclusion number density and the smaller characteristic inclusion radius than other parts inside the mold. And the characteristic inclusion concentration and the characteristic inclusion number density decrease gradually during the marching of fresh molten steel because some inclusions are trapped by the solidified shell on the broad face. But the characteristic inclusion radius increases gradually during the marching of fresh molten steel because of the collision and coalescence among inclusions.

Figures 6-8 also show that inclusion motion also follows fluid flow. The distributions for the characteristic inclusion concentration, the characteristic inclusion number density, and the characteristic inclusion radius also have the upper and lower recirculation zones. But near the center of the recirculation, the characteristic inclusion concentration and the characteristic inclusion number density are lower but the characteristic inclusion radius is higher. Several reasons lead to such a interesting phenomenon. Firstly, top slag continues to absorb the inclusions in the molten steel. And bigger inclusions have more chances to float up and to be removed by top slag. Secondly, the solid-liquid interface

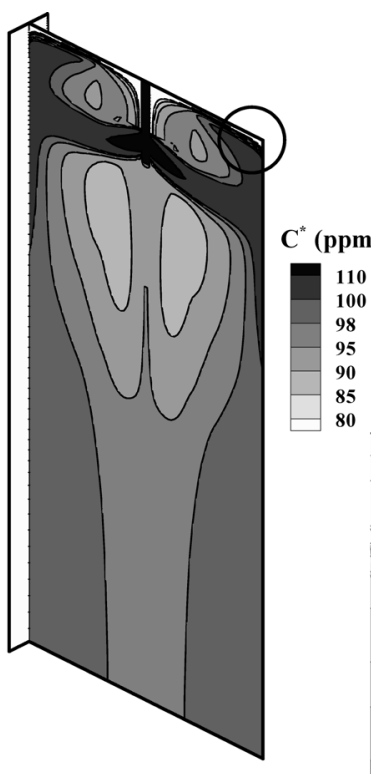

(a) three-dimensional distribution

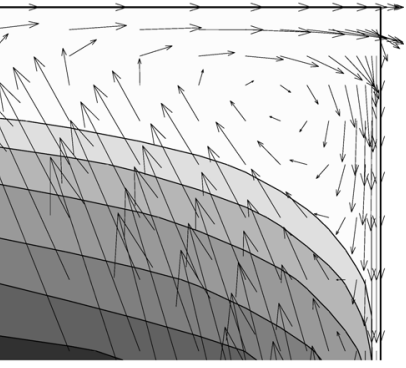

(b) enlarged part
Fig. 6. Characteristic inclusion concentration in the continuous caster. (a) Three-dimensional distribution, (b) enlarged part. 


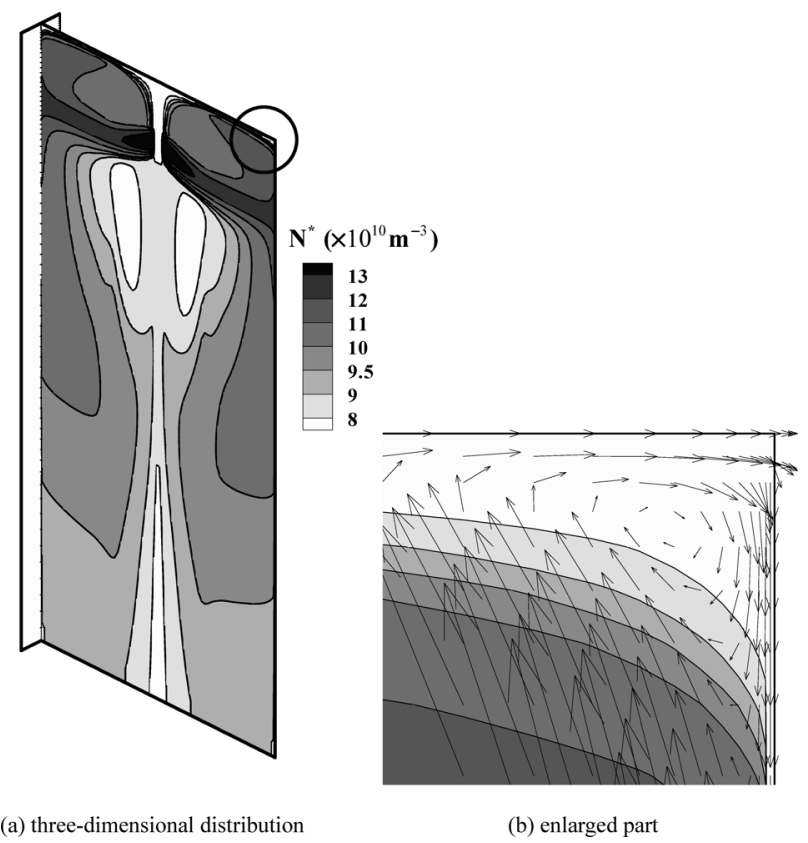

Fig. 7. Characteristic inclusion number density in the continuous caster. (a) Three-dimensional distribution, (b) enlarged part.

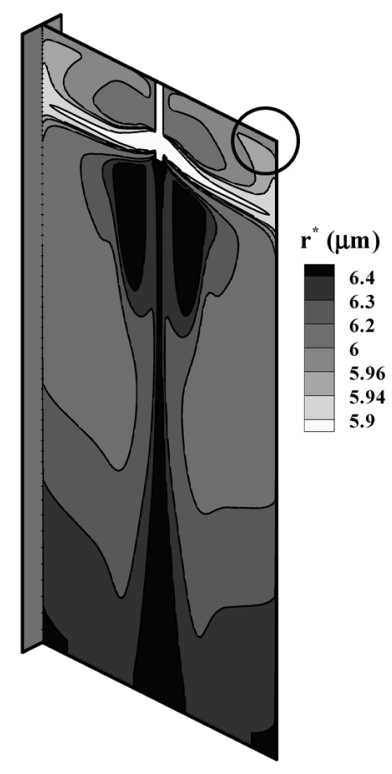

(a) three-dimensional distribution

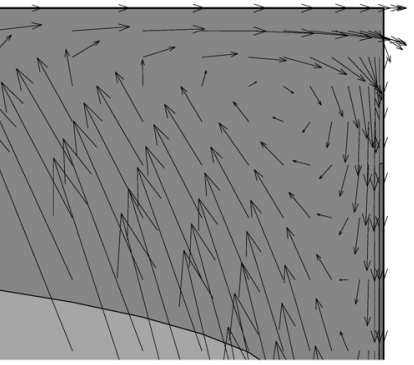

(b) enlarged part
Fig. 8. Characteristic inclusion radius in the continuous caster. (a) Three-dimensional distribution, (b) enlarged part

continues to trap the inclusions in the mushy zone. Thirdly, near the center of the recirculation zone, the fluid velocity is so small that the fresh molten steel cannot enter this region. Fourthly, more big inclusions appear and float up due to the collision and coalescence among inclusions, but the characteristic inclusion concentration is diluted by the fresh molten steel from the nozzle while these bigger inclusions pass through the neighborhood of nozzle entry. Fifthly, a few of inclusions can reach the center of the recirculation zone after many loop movements. Thus, they have enough time to collide with other inclusions and become bigger inclusions.

Figures 6(a), 7(a) and 8(a) show that there are a few of small inclusions in the initial solidified shell. It should be noted that these inclusions are indigenous inclusions, not exogenous inclusions. Three reasons result in such a phenomenon. Firstly, Fig. 6(b) shows that there is a small corner-vortex near the meniscus because of the interaction between the movement of solidified shell and the downward flow. In another word, a fraction of upward flow moves toward the meniscus. With the help of slag's absorption, such a short-circuit flow forms a small 'clean' region where the inclusion concentration is low and the inclusions have small size, as shown in Figs. 6(b), 7(b) and 8(b). Secondly, the initial solidified shell forms at the meniscus, only a few of inclusions with small size can be trapped by the solid-liquid interface. Thirdly, the initial solidified shell moves at casting speed, but the inclusions in the solid shell cannot collide with each other, so the inclusion in the solidified shell at the exit has the same distribution as that near the meniscus.

Figure 8(a) shows that the characteristic inclusion radius is bigger ahead of the solid-liquid interface. Such an interesting phenomenon comes from the ' $\mathrm{W}$ '-shape velocity distribution at the exit, as shown in Fig. 2. Because it is easier for the small inclusion to be entrained by the steel stream, bigger inclusions are remained near the solid-liquid interface. Figure 8(a) also shows that the characteristic inclusion radius is bigger near the center of the exit due to the collision and coalescence among inclusions.

\section{Conclusions}

(1) A coupled mathematical model, which consists of momentum, heat and mass transfer, is developed to describe fluid flow, heat transfer, solidification, solute transfer and inclusion collision-growth in the continuous casting process. The governing equations can be expressed as a general differential equation, so they can be solved by finite-volume method on the base of staggered grid.

(2) The heat and mass transfer follows the momentum transfer. The distributions of velocity, temperature, carbon element and inclusion have the upper and lower recirculation zones. But near the center of the recirculation zone, the temperature, characteristic inclusion concentration and characteristic inclusion number density are lower, but the carbon concentration and the characteristic inclusion radius are higher.

(3) Due to the interaction between the movement of solidified shell and the downward flow, a small corner-vortex, where the inclusion concentration is low and the inclusion size is small, appears near the meniscus. Because the initial solidified shell forms at the meniscus, there are a few of small inclusions in the initial solidified shell.

(4) At the exit, the velocity distribution has a 'W'shape, and it is easier for small inclusions to be entrained by the steel stream, so there are bigger inclusions ahead of the solid-liquid interface. Due to the collision and coalescence among inclusion, there is bigger inclusions near the center of the exit.

\section{Acknowledgements}

This work was supported by the National High-tech R\&D Program of China (No. 2009 AA03Z530), the Na- 
tional Natural Science Foundation of China and Shanghai Baosteel (No. 50834010), the Key Project of Chinese Ministry of Education (No. 108036), SRF for ROCS, SEM (20071108-2) and NEU, 111 Project (No. B07015), China Postdoctoral Science Foundation (No. 20070421065) and Northeastern University Postdoctoral Science Foundation.

\section{REFERENCES}

1) B. G. Thomas, L. M. Mika and F. M. Najjar: Metall. Trans. B, 21B (1990), 387.

2) Q. Yuan, B. G. Thomas and S. P. Vanka: Metall. Mater. Trans. B, 35B (2004), 685 .

3) M. R. Aboutalebi, M. Hasan and R. I. L. Guthrie: Metall. Mater. Trans. B, 26B (1995), 731.

4) H. L. Yang, L. G. Zhao, X. Z. Zhang, K. W. Deng, W. C. Li and Y. Gan: Metall. Mater. Trans. B, 29B (1998), 1345.

5) M. DeSantis and A. Ferretti: ISIJ Int., 36 (1996), 673.

6) M. Javurek, P. Gittler, R. Rossler, B. Kaufmann and H. Presslinger: Steel Res. Int., 76 (2005) 64.

7) C. H. Moon and S. M. Hwang: Ironmaking Steelmaking, 30 (2003), 48.

8) H. Lei, L. Z. Wang, Z. N. Wu and J. F. Fan: ISIJ Int., 42 (2002), 717.

9) H. Lei and J. C. He: Steel Res. Int., 78 (2007), 704.

10) H. Lei and J. C. He: J. Non-Cryst. Solids, 352 (2006), 3772.

11) M. Y. Ha, H. G. Lee and S. H. Seong: J. Mater. Process. Technol., 133 (2003), 322.

12) K. Nakanishi and J. Szekely: Trans. Iron Steel Inst. Jpn., 15 (1975), 522.

13) Y. Miki and B. G. Thomas: Metall. Mater. Trans. B, 30B (1999), 639.

14) H. Tozawa, Y. Kata, K. Sorimachi and T. Nakanishi: ISIJ Int., 39 (1999), 426.

15) L. F. Zhang, S. Taniguchi and K. K. Cai: Metall. Mater. Trans. B, 31B (2000), 253

16) L. Zhang: Steel Res. Int., 76 (2005), 784.

17) S. Linder: Scand. J. Metall., 3 (1974), 137.

18) S. V. Patankar: Numerical Heat Transfer and Fluid Flow. Hemisphere Pub. Co., Washington, (1980), 15.

19) Y. H. Ho and W. S. Hwang: ISIJ Int., 43 (2003), 1715.

20) L. Zhang, Y. Wang and W. Zuo: Metall. Mater. Trans. B, 39B (2008), 534.

21) H. Zhang, E. Wang and J. He: Acta Metall. Sin., 38 (2002), 99.

22) K. G. Kang, H. S. Ryou and N. K. Hur: Numer. Heat Transfer, 48A (2005), 461

23) S. H. Seyedein and M. Hasan: Int. J. Heat Mass Transfer, 40 (1997), 4405.

24) H. B. Shi, G. H. Gao and Y. X. Yu: Fluid Phase Equilib., 228 (2005), 535.

25) H. Lei: Ph. D. Thesis, Northeastern University, Shenyang, China, (2001).
Appendix. Derivation for Turbulent Collision and Stokes Collision in Inclusion Population Balance Equation

The turbulent effect on the inclusion collision-coalescence is incorporated into the inclusion population balance equation by defining the following source terms:

$$
\begin{aligned}
S_{\text {turb }} & =\frac{1}{2} \int_{0}^{\infty} \int_{0}^{\infty} 1.3 \sqrt{\frac{\pi \varepsilon}{v}}\left(r_{i}+r_{j}\right)^{3} n_{i} n_{j} d r_{i} d r_{j} \\
& =\frac{1}{2} \int_{0}^{\infty} \int_{0}^{\infty} 1.3 \alpha \sqrt{\frac{\pi \varepsilon}{v}}\left(r_{i}+r_{j}\right)^{3} A e^{-B r_{i}} A e^{-B r_{j}} d r_{i} d r_{j} \\
& =\frac{1}{2} \int_{0}^{\infty} \int_{r_{i}}^{\infty} 1.3 \alpha \sqrt{\frac{\pi \varepsilon}{v}} R^{3} A^{2} e^{-B R} d R d r_{i} \\
& =1.3 \alpha \sqrt{\frac{\pi \varepsilon}{v}} \frac{12 A^{2}}{B^{5}}=2.6 \alpha \sqrt{\frac{\pi \varepsilon}{v}} N^{* 2} r^{* 3}
\end{aligned}
$$

The effect of Stokes flotation on the inclusion collisioncoalescence is incorporated into the inclusion population balance equation by defining the following source terms:

$$
\begin{aligned}
S_{\text {Strokes }}= & \frac{1}{2} \int_{0}^{\infty} \int_{0}^{\infty} \frac{2 \pi g \Delta \rho}{9 \mu}\left|r_{i}^{2}-r_{j}^{2}\right|\left(r_{i}+r_{j}\right)^{2} n_{i} n_{j} d r_{i} d r_{j} \\
= & \frac{1}{2} \int_{0}^{\infty} \int_{0}^{\infty} \frac{2 \pi g \Delta \rho}{9 \mu}\left|r_{i}-r_{j}\right|\left(r_{i}+r_{j}\right)^{3} A e^{-B r_{i}} A e^{-B r_{j}} d r_{i} d r_{j} \\
= & \int_{0}^{\infty} \int_{r_{i}}^{\infty} \frac{\pi g \Delta \rho}{9 \mu}\left|2 r_{i}-R\right| R^{3} A^{2} e^{-B R} d R d r_{i} \\
= & \int_{0}^{\infty} \int_{2 r_{i}}^{\infty} \frac{\pi g \Delta \rho}{9 \mu}\left(R-2 r_{i}\right) R^{3} A^{2} e^{-B R} d R d r_{i} \\
& +\int_{0}^{\infty} \int_{r_{i}}^{2 r_{i}} \frac{\pi g \Delta \rho}{9 \mu}\left(2 r_{i}-R\right) R^{3} A^{2} e^{-B R} d R d r_{i} \\
= & \frac{\pi g \Delta \rho}{9 \mu} \frac{60 A^{2}}{B^{6}}=\frac{10}{9 \sqrt[3]{6}} \frac{\pi g \Delta \rho}{\mu} N^{* 2} r^{* 4}
\end{aligned}
$$

